\title{
Study on calculation method of stability for embedded penstocks with stiffener ring under external pressure
}

\author{
WANG Bifei ${ }^{1, *}$, LI Yuewei ${ }^{1, * *}$, QI Wenqiang ${ }^{1, * * *}$, WANG Qihang ${ }^{1, * * * *}$ \\ ${ }^{1}$ Changjiang Institute of Survey, Planning, Design and Research, Wuhan 430010, China
}

\begin{abstract}
A three-dimensional FEM(finite element model)is established, including penstocks with initial defect (ovality), backfill concrete, drainage cushion and surrounding rock. The nonlinear static calculation of the model is carried out. The stability of penstocks with backfill concrete, drainage cushion and surrounding rock under external pressure is studied. The sensibility of the embedded penstocks to initial defect, initial gap and elastic modulus of drainage cushion is analyzed. The results of finite element method, Jacobsen method and strength formula in SL281 are compared and analyzed. The results indicate that the FEM of penstocks, backfill concrete and surrounding rock with initial defects is easy to converge by nonlinear calculation; the ovality and gap have little influence on the critical external pressure of the embedded penstocks with stiffener ring, while the drainage cushion has a certain influence on the critical external pressure; the critical external pressure calculated by SL281 is low and safe; compared with Jacobsen method, the critical external pressure of the finite element method is increased by about $14 \%$; for the embedded penstocks with drainage cushion, the finite element method can be used to calculate the influence of the drainage cushion on the critical external pressure, and the appropriate reduction factor can be obtained, and then the Jacobsen result can be modified by the reduction factor.
\end{abstract}

\section{Introduction}

The external pressure stability of embedded penstocks with stiffener ring includes the stability of the pipe wall between the stiffener rings and the stability of the stiffener rings. Mises formula is recommended in most domestic and foreign codes to calculate the stability of the pipe wall between the stiffener rings. The calculation methods of the stability of the stiffener rings generally include Amstutz method $^{[1]}$, Jacobsen method ${ }^{[2]}$, Svoisky method ${ }^{[3]}$ and formula (B.2.2) in Specification SL281 ${ }^{[4]}$. Mises formula assumes that the penstocks is a short cylinder exposed pipe, and both ends of the penstocks are rigidly restrained by the stiffener ring. Chinese codes, the United States and Japan all recommend using Mises formula to calculate the stability of the pipe wall between the stiffener rings. For embedded penstocks, Mises formula does not quantitatively calculate the increase of the critical external pressure of the penstock due to the radial restraint of concrete. As a safety reserve, the safety factor of embedded penstocks is 1.8 and that of exposed penstocks is 2 as SL281 ${ }^{[4]}$. Amstutz, Jacobsen, Svoisky, etc. based on the elastic theory, assumed that the penstocks is an ideal round pipe and the material is linear elastic, simplified as a plane strain problem, derived the analytical formula of the stiffener ring stability against external pressure. Due to the complexity of the above formula, the formula (B2.2.2) in SL281 refers to the provisions of the U.S. Bureau of Reclamation and is controlled by the strength condition.

*goldentree_sz@sina.com, ${ }^{* *}$ liyuewei@cjwsjy.com.cn,

*** qiwenqiang@cjwsjy.com.cn, ${ }^{* * * *}$ wangqihang@cjwsjy.com.cn

(c) The Authors, published by EDP Sciences. This is an open access article distributed under the terms of the Creative Commons Attribution License 4.0

(http://creativecommons.org/licenses/by/4.0/).
The design load of the stiffener ring is taken as all the external pressure within the stiffener ring spacing, and the sum of the cross-sectional area of the stiffener ring and the effective flange area of the pipe wall is assumed to resist the external pressure. For the deep embedded penstock, the external water pressure is generally high, and considering the economic rationality, the pressure reduction design though drainage should be carried out. The composite drainage cushion is one of the drainage methods used in the project. The external water is discharged along the drainage cushion, which can reduce the external water pressure. However, the drainage cushion is a kind of flexible material, and relevant codes and elastic theory assume that the material of the outer of pipe is rigid.

The external pressure instability of embedded penstocks is related to the elastic-plastic mechanical properties of materials, the initial gap between penstocks and backfill concrete, and the initial defects of penstocks, which is a complex geometric and material nonlinear problem. Many scholars have carried out in-depth research on nonlinear calculation and analysis ${ }^{[5-8]}$. In reference $^{[5]}$, ANSYS is used to calculate the critical external pressure. The basic idea is to use buckling module to calculate the eigenvalue and eigenvector of the structure. The eigenvector corresponds to the instability mode of the structure. The first-order instability mode of the structure is extracted, and the UPGEOM command is used to add initial defects to the structure according to the first-order instability mode. The first-order instability mode is 
imported into the three-dimensional model in a certain proportion as the initial geometric defects. The nonlinear static calculation is carried out, and the load increment is gradually applied to make the structural stiffness change until the stiffness matrix approaches singularity. At this time, the load is the critical external pressure. In reference[6], ABAQUS is used to analyze the buckling of exposed penstocks with stiffener ring, which is basically consistent with the method in reference[5]. In reference[7], based on the exact formula of buckling and the approximate formula adopted in design, the expression of the critical spacing of stiffener rings is derived for exposed penstocks with stiffener rings, and the results are compared with those of finite element calculation. Literature[5-7] studies the exposed penstocks with stiffener ring. Literature[8] calculates and analyzes the socalled pre-buckling and post-buckling modes of embedded penstocks. This method is effective for the exposed penstocks. The embedded penstocks is a composite structure, and the contact element between the penstock and the backfill concrete should be separated, which is a nonlinear problem. The buckling module can only carry out elastic analysis, ignoring the non-linear effect. The calculation results only include the instability mode of the penstocks, and there is no instability between concrete and surrounding rock. When the UPGEOM command is used to add initial defects to the structure according to the instability mode, the initial geometric defects appear in the penstocks, and there is no initial geometric defects between the backfill concrete and the surrounding rock. The uncoordinated deformation between the penstocks and the backfill concrete leads to the penetration of the contact pair between the penstocks and the backfill concrete, especially when the initial deformation is large, the calculation is not easy to converge

In this paper, a three-dimensional FEM of penstocks, backfill concrete, drainage cushion and surrounding rock with initial defects is established to calculate the critical external pressure. The UPGEOM command is not needed to import the initial defects. The material nonlinearity and geometric nonlinearity are also considered in the calculation. The nonlinear static analysis of the model is carried out, and the curve of load and displacement is obtained, in which the highest point of the curve is the critical external pressure. The method of FEM avoids the deformation disharmony between the penstocks and the outer body (backfill concrete, drainage cushion) caused by the reintroduction of initial defects in the model. In the established model, the shape of the outer surface of the penstocks and the inner surface of the outer body are consistent, the initial defects of the penstocks do not affect the gap between the penstocks and the outer body, and the calculation is easy to converge.

\section{Finite element analysis}

\subsection{Project survey}

The diameter of main pipe of embedded penstocks in a hydropower station is $3.0 \mathrm{~m}$, and the embedded depth of penstock is $100-300 \mathrm{~m}$. The bedrock of diversion tunnel is dominated by class III surrounding rock, and there are class IV or class $\mathrm{V}$ surrounding rock locally. It is speculated that the groundwater level is about $20 \mathrm{~m}$ under the ground surface. The space between the penstocks and the tunnel is backfilled with concrete. The thickness of the backfill concrete is about $400 \mathrm{~mm}$, and the grade is $\mathrm{C} 30$. The elastic modulus is $30 \mathrm{GPa}$, and the Poisson's ratio is 0.167 . The elastic modulus of surrounding rock is $2 \mathrm{GPa}-$ $8 \mathrm{GPa}$, and Poisson's ratio is 0.25 . The elastic modulus of penstocks materials is $206 \mathrm{GPa}$, and Poisson's ratio is 0.3 . The tensile strength is $\sigma_{b}=610 \mathrm{MPa}$, according to SL281 ${ }^{[4]}$, the yield strength is $\sigma_{\mathrm{S}}=0.7 \times 610=427 \mathrm{MPa}$. The thickness of pipe wall is $20 \mathrm{~mm}$. The height of stiffener ring is $180 \mathrm{~mm}$, and the thickness of stiffener ring is $20 \mathrm{~mm}$. The spacing between stiffener rings is $1500 \mathrm{~mm}$. In order to reduce the external water pressure, the outer pipe wall of the upper semicircle is wrapped with $50 \mathrm{~mm}$ thick drainage plate, and the elastic modulus of the drainage plate is $1 \mathrm{MPa}$.

\subsection{Finite element model}

The eigenvalue buckling analysis in ANSYS assumes that the physical equation and geometric equation are linear. The eigenvalue buckling analysis is used to predict the theoretical buckling strength (bifurcation point) of an ideal elastic structure. The elastic buckling analysis method is used to obtain the buckling modes and eigenvalues of the structure. The solution of each buckling mode is actually an eigenvalue solution problem. In nonlinear buckling analysis, geometric and material nonlinearities are introduced to obtain the relationship curve of structural displacement and load. The highest point of curve is the ultimate bearing capacity of the structure. Nonlinear buckling analysis is a static analysis when the switch of large deformation effect is turned on, which can be solved by arc length method. Eigenvalue buckling calculation is convenient and fast, but it does not take into account the initial defects of the structure, material nonlinearity and geometric nonlinearity. So the calculation results are often larger. Compared with the linear calculation results, the nonlinear calculation results are more accurate.

In order to find out the factors influencing the stability of embedded penstocks under external pressure, four FEM are established.

Calculation model 1: exposed model with stiffener ring. In order to reduce the influence of boundary conditions on the calculation results, the penstocks is taken as $60 \mathrm{~m}$ along the length direction, and fixed constraints are imposed on both ends of the penstocks. Eigenvalue buckling is used to analyze the eigenvalues and instability modes of the stiffener and penstocks. The calculation can be divided into two cases: (1) the overall stability of the penstocks (the external pressure stability of the stiffener ring) is calculated when the stiffener ring is not constrained; (2) the stability of the pipe wall between the stiffener rings is calculated when the stiffener ring is fixed, which is compared with Mises formula.

Calculation model 2: exposed penstocks model with stiffener ring. The initial defect of penstocks is introduced 
in the modeling. The penstocks takes different ovality. The shape of inner ring of stiffener ring is the same as that of the outer of pipe wall, which is ellipse. The outer ring is circle. The penstocks takes $60 \mathrm{~m}$ along the length direction. The two ends of penstocks are subject to fixed constraints, and the outer of pipe wall is subject to external water pressure. Nonlinear static calculation is adopted.

Calculation model 3: embedded penstock model with stiffener ring. On the basis of Calculation model 2, the relationship between backfill concrete and surrounding rock is established. The initial gap and the initial defect of the penstocks are introduced in the modeling. The initial gap takes different values. The model takes $60 \mathrm{~m}$ along the length direction of the penstock. The distance between the boundary of the model and the center of the penstocks is more than 3 times of the penstocks diameter. The fixed constraint is imposed on the bottom of the surrounding rock, the symmetrical constraint is imposed on the other boundary surfaces, and the external pressure is imposed on the outer of pipe wall. Nonlinear static calculation is adopted.

Calculation model 4: Based on calculation model 3, 50 $\mathrm{mm}$ thick drainage cushion is established. Nonlinear static calculation is adopted.

The linear elastic constitutive model is adopted in the Calculation model 1. In the Calculation model 2, the double broken line equal strength hardening constitutive model is adopted, and the continuous stress-strain curve is approximately two straight lines. The first line represents the linear elastic deformation property with a slope of E; the second line represents the hardening property with a slope of Et. The stress at the intersection of the two lines is the yield strength. Below the yield strength, the material is elastic. Beyond the yield strength, the material shows elastic-plastic properties, and $\mathrm{Et}$ is $3 \mathrm{E} / 100$. The constitutive model of penstocks in Calculation model 3 is the same as that in Calculation model 2, which is nonlinear. The linear elastic constitutive model is adopted for surrounding rock and backfill concrete. The backfill concrete and surrounding rock share a common node, and the elastic modulus of surrounding rock is $2 \mathrm{GPa}$. The mechanical model of contact relationship is adopted for the interaction between backfill concrete and penstocks. The contact model is Coulomb friction, the normal compressive stiffness is infinite, and the normal tensile stiffness is 0 . When the tangential shear stress reaches the friction determined by the friction coefficient of normal pressure or the ultimate side friction, the interface can slide relatively. The friction coefficient between concrete and penstocks is 0.4 , and the maximum friction between concrete and penstocks is not more than $0.2 \mathrm{MPa}$. The penstocks is simulated by shell element, the concrete and surrounding rock are simulated by solid element, and the contact relationship is simulated by contact element. The FEM of embedded penstock of Calculation model 3 is shown in Figure 1.

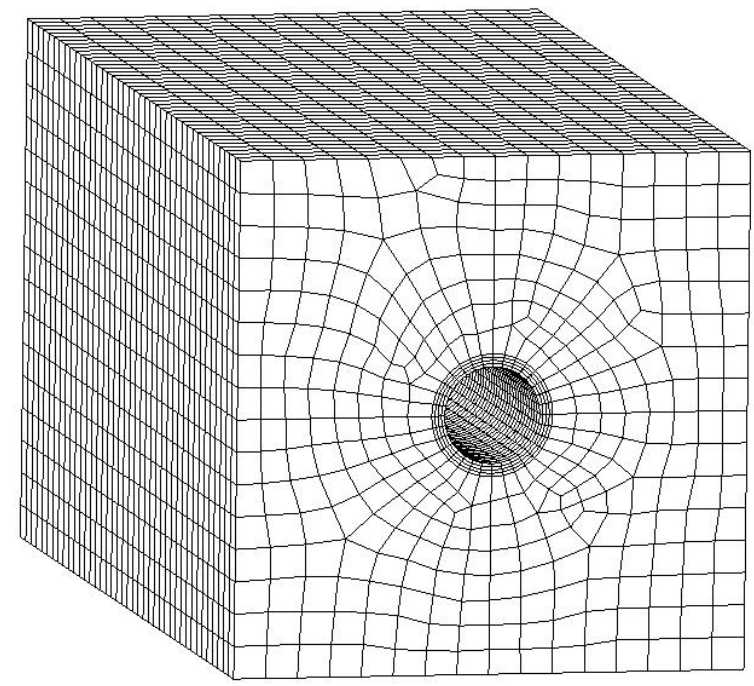

Figure 1. FEM of embedded penstocks

\section{Calculation results}

\subsection{Eigenvalue buckling analysis}

The eigenvalue buckling mode of stiffener ring penstocks under $1 \mathrm{MPa}$ uniform external pressure is calculated, and the eigenvalue is the critical external pressure. The results show that: (1) when the stiffener ring is not constrained, the buckling wave number between the stiffener ring and the pipe wall is 2 , and the critical external pressure is 3.02MPa. The first buckling modes of stiffener rings and penstocks shown in Figure 2. (2) the buckling wave number of the pipe wall between stiffeners is 8 and the critical external pressure is $4.75 \mathrm{MPa}$. The buckling wave number calculated by Mises formula is 8 and the critical external pressure is $4.35 \mathrm{MPa}$. The critical external pressure calculated by eigenvalue buckling is $8.42 \%$ higher than that calculated by Mises. The first buckling mode of the pipe wall between stiffeners is shown in Figure 3.

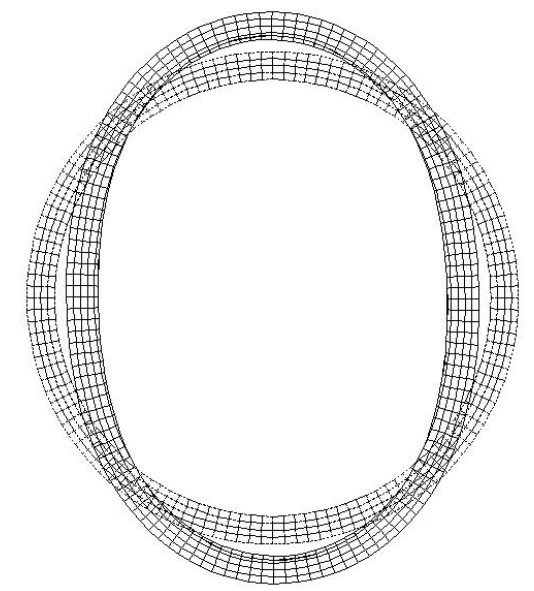

Figure 2. Buckling mode of stiffener ring and pipe wall 


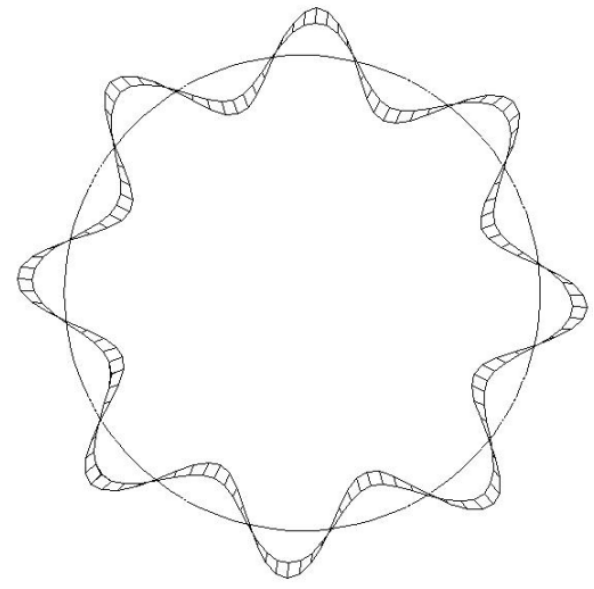

Figure 3. Buckling mode of pipe wall

\subsection{Influence of ovality}

For the ideal shape of penstocks when the finite element calculation is used, under the symmetrical external pressure, the penstocks will have compression yield failure due to insufficient strength, and the external pressure of yield failure is far greater than the critical external pressure theoretically solved. Therefore, to analyze the stability of penstocks under external pressure, initial defects are required to is imposed on the penstocks. In this paper, the ovality of penstocks is imposed on penstocks as initial defect. Specification GB50766-2012 ${ }^{[9]}$ stipulates that the ovality of penstocks shall not be greater than 3D/1000. In Calculation model 2 and 3, the ovality of 3D/1000, 6D/1000, 9D/1000, 12D/1000, 15D/1000, $18 \mathrm{D} / 1000$ and $21 \mathrm{D} / 1000$ ( $\mathrm{D}$ is the diameter of penstocks) is selected for series calculation, and the gap between penstocks and backfill concrete in Calculation model 3 is taken as $0.8 \mathrm{~mm}$.

The relationship curve of critical external pressure of penstocks and ovality is shown in Figure 4, and the relationship curve of max. radial compressive stress of concrete and ovality is shown in Figure 5. The results show that: (1) The critical external pressure of exposed penstocks is sensitive to the ellipticity. The critical external pressure decreases with the increase of ellipticity. The critical external pressure corresponding to the ovality of $3 \mathrm{D} / 1000$ and $21 \mathrm{D} / 1000$ is $2.58 \mathrm{MPa}$ and $1.86 \mathrm{MPa}$ respectively. The critical external pressure calculated by the buckling of the exposed penstocks is $3.02 \mathrm{MPa}$, which is reduced by $14.6 \%$ and $38.4 \%$ compared with eigenvalue. (2) Due to the radial restriction of backfill concrete and the restraint effect of stiffening ring, the critical external pressure of embedded penstocks is less affected by ovality. The corresponding critical external pressure of ovality $3 \mathrm{D} / 1000$ and $21 \mathrm{D} / 1000$ is $5.78 \mathrm{MPa}$ and $5.68 \mathrm{MPa}$ respectively. At the same time, the circumferential compressive stress of penstocks is also less affected by ovality. The maximum circumferential compressive stress corresponding to ovality $3 \mathrm{D} / 1000$ and $21 \mathrm{D} / 1000$ is $475.95 \mathrm{MPa}$ and $453.28 \mathrm{MPa}$ respectively. (3) The maximum radial compressive stress of concrete increases with the increase of ellipticity. When the ellipticity is small, the buckling amplitude of penstocks is small, and the radial restraint of concrete to penstocks is small and vice versa. The radial compressive stress of concrete corresponding to ellipticity $3 \mathrm{D} / 1000$ and $21 \mathrm{D} / 1000$ is $0.402 \mathrm{MPa}$ and $1.111 \mathrm{MPa}$ respectively, which is far less than the compressive strength of concrete. (4) When the exposed penstocks is unstable, the maximum circumferential stress occurs on the stiffener ring, which is $445.85 \mathrm{MPa}$, while the circumferential stress of the pipe wall is relatively low. When the embedded penstocks is unstable, the maximum circumferential stress occurs on the pipe wall, which is $475.95 \mathrm{MPa}$. Most of the stress of the pipe wall exceeds the yield strength of the steel, indicating that the radial restraint of the backfill concrete can improve the external pressure resistance of the penstocks.

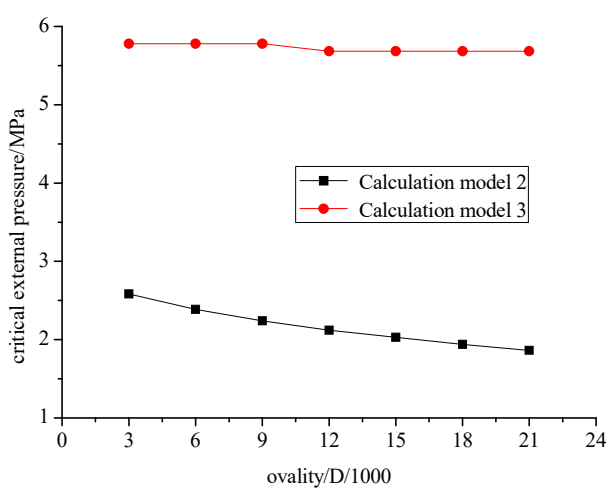

Figure 4. Relationship curve of critical external pressure of penstocks and ovality

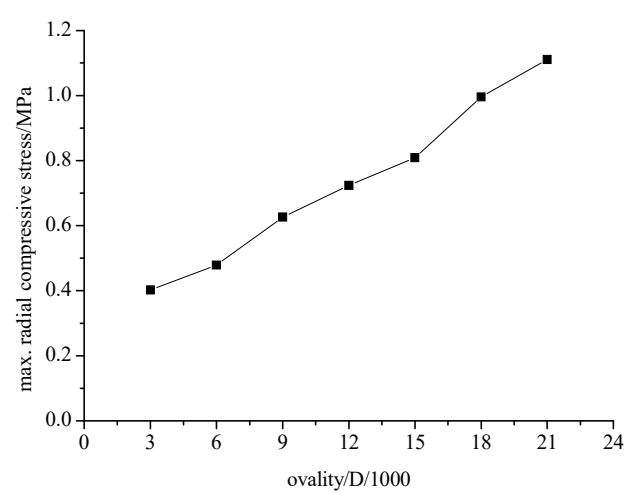

Figure 5. Relationship curve of max. radial compressive stress of concrete and ovality

\subsection{Influence of gap}

There is an initial gap between the penstocks and the backfill concrete, and the gap fluctuation range is large. Its size is related to the quality of concrete casting and grouting. The critical external pressure under different gaps is calculated. The gap is $0 \mathrm{~mm}, 0.4 \mathrm{~mm}, 0.8 \mathrm{~mm}$, $1.2 \mathrm{~mm}, 1.6 \mathrm{~mm}$ and $2.0 \mathrm{~mm}$ respectively. In order to directly express the relationship between the gap and the radius of the penstocks, the corresponding gap can also be expressed as $0,2.7 \times 10^{-4} \mathrm{r}, 5.3 \times 10^{-4} \mathrm{r}, 8.0 \times 10^{-4} \mathrm{r}, 10.7 \times 10^{-4} \mathrm{r}$ and $13.3 \times 10^{-4} \mathrm{r}$. The ovality of the penstocks is $3 \mathrm{D} / 1000$.

The critical external pressure of different gaps is shown in Table 1. The relationship curve of critical external pressure of penstocks and gap is shown in Figure 6 , and relationship curve of max. radial compressive stress 
of backfill concrete and gap is shown in Figure 7. The results show that: (1) The formula (B.2.2) in SL281 of the critical external pressure is controlled by strength condition, which is inconsistent with the concept of buckling instability. The critical external pressure calculated by SL281 is $1.78 \mathrm{MPa}$, which is the smallest. Jacobsen's critical external pressure is much larger than that calculated by SL281 due to considering the restraint effect of backfill concrete. Many engineering examples show that the calculated results by SL281 are conservative. (2) Jacobsen's method assumes that there is only one local buckling instability region along the circumferential, and ignores the interaction between the pipe wall outside the equivalent flange. In fact, when the instability of penstocks occurs, the penstocks will wrinkle and interact with each other, which the FEM can simulate this interaction. The interaction between the penstocks and the backfill concrete and the hardening of the steel can be considered. The critical external pressure calculated by

Table1. Critical external pressure of stiffener ring with different gaps/MPa

\begin{tabular}{|c|c|c|c|c|c|}
\hline gap/mm & Jacobsen & $\begin{array}{c}\text { Specification } \\
\text { SL281 }\end{array}$ & $\begin{array}{c}\text { Calculation } \\
\text { model } 1\end{array}$ & $\begin{array}{c}\text { Calculation } \\
\text { model } 2\end{array}$ & $\begin{array}{c}\text { Calculation } \\
\text { model } 3\end{array}$ \\
\hline 0 & 5.07 & - & - & - & 5.78 \\
\hline 0.4 & 4.94 & - & - & - & 5.78 \\
\hline 0.8 & 4.83 & - & - & - & 5.78 \\
\hline 1.2 & 4.74 & - & - & - & 5.68 \\
\hline 1.6 & 4.65 & - & - & - & 5.59 \\
\hline 2.0 & 4.57 & - & - & - & 5.59 \\
\hline $\begin{array}{c}\text { without } \\
\text { consideration }\end{array}$ & - & 1.78 & 3.02 & 2.58 & - \\
\hline
\end{tabular}

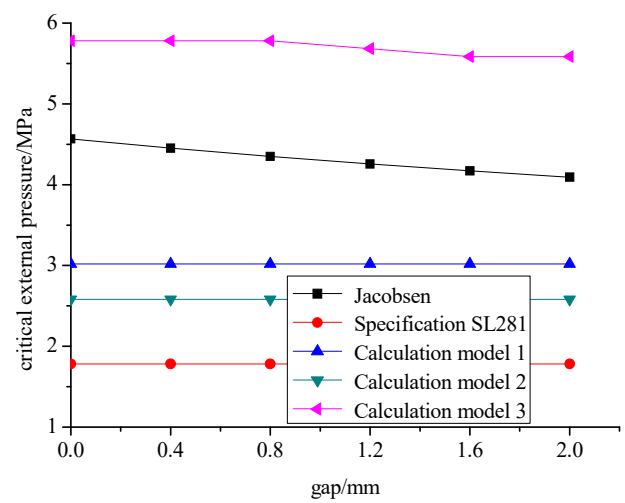

Figure 6. Relationship curve of critical external pressure of
Figure 6. Relationship curve of critical
penstocks and gap
FEM is higher than that calculated by Jacobsen method. (3) Due to the radial restriction of backfill concrete and the restraint of stiffener ring, the critical external pressure of embedded penstocks is less affected by the gap. The critical external pressure corresponding to the gap of $0 \mathrm{~mm}$ and $2 \mathrm{~mm}$ is $5.78 \mathrm{MPa}$ and $5.59 \mathrm{MPa}$ respectively. At the same time, the circumferential compressive stress of penstocks is less affected by the gap. The maximum circumferential pressure stress corresponding to the gap $0 \mathrm{~mm}$ and $2 \mathrm{~mm}$ is $475.60 \mathrm{MPa}$ and $470.14 \mathrm{MPa}$ respectively. (5) The maximum radial compressive stress of concrete increases with the increase of the gap. When the gap is small, the buckling wave amplitude of penstocks is small, and the pressure transmitted to concrete by convex buckling wave of penstocks is small and vice versa. The radial compressive stress of concrete with the gap of $0 \mathrm{~mm}$ and $2 \mathrm{~mm}$ is $0.288 \mathrm{MPa}$ and $0.572 \mathrm{MPa}$ respectively, which is far less than the compressive strength of concrete.

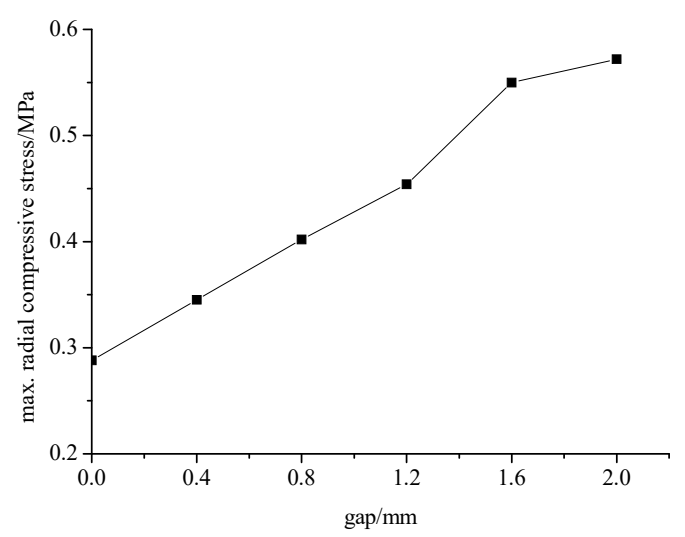

Figure 7. Relationship curve of max. radial compressive stress of concrete and gap

\subsection{Influence of drainage cushion}

The elastic modulus of drainage cushion commonly used in engineering ranges from 1 to $5 \mathrm{MPa}$. The critical external pressures of $1 \mathrm{MPa}, 3 \mathrm{Mpa}$ and $5 \mathrm{MPa}$ are calculated in Calculation model 4, without considering the influence of gap. The critical external pressure of different elastic modulus is shown in Table 2. When Jacobsen method is used to calculate the critical external pressure, it is assumed that the stiffness of the outer body of 
penstocks is infinite. In Calculation model 3, the outside of the penstocks is backfilled with concrete, and the elastic modulus is $30 \mathrm{GPa}$. The results show that after adding drainage cushion, the critical external pressure is reduced, and the softer the drainage cushion is, the more the critical external pressure decreases. The critical external pressure corresponding to the elastic modulus of $1 \mathrm{MPa}, 3 \mathrm{Mpa}$ and $5 \mathrm{MPa}$ is $5.26 \mathrm{MPa}, 5.44 \mathrm{MPa}$ and $5.66 \mathrm{MPa}$ respectively. Compared with the Calculation model 3 , the critical external pressure is $5.78 \mathrm{MPa}$, and the critical external pressure corresponding to the elastic modulus $1 \mathrm{MPa}$ of the drainage cushion decreases by $9.0 \%$.

Table2. Critical external pressure of stiffener ring with different elastic modulus/MPa

\begin{tabular}{cccccc}
\hline & Jacobsen & $\begin{array}{c}\text { Calculation } \\
\text { model 3 }\end{array}$ & \multicolumn{3}{c}{ Calculation model 4 } \\
\hline $\begin{array}{c}\text { elastic modulus } \\
\text { /MPa }\end{array}$ & infinity & 30000 & 1 & 3 & 5 \\
$\begin{array}{c}\text { critical external } \\
\text { pressure/MPa }\end{array}$ & 5.07 & 5.78 & 5.26 & 5.44 & 5.66 \\
\hline
\end{tabular}

\section{Conclusion}

(1) Many engineering examples show that the critical external pressure calculated by SL281 is too conservative.

(2) Jacobsen's method is mature and has a wide range of application, but it has some limitations for calculating the critical external pressure of embedded penstocks with soft cushion.

(3) A three-dimensional FEM with initial defects is established. The shape of the contact surface between the outer wall of pipe and the concrete is the same. The contact pair between the two will not penetrate, and the calculation is easy to converge. Compared with Jacobsen method, the critical external pressure of finite element method is increased by about $14 \%$. Whether this method is suitable for practical engineering design remains to be verified.

(4) For embedded penstocks with soft cushion, the finite element method can be used to calculate the influence of soft cushion on the critical external pressure, and the appropriate reduction factor can be obtained, and then the Jacobsen result can be modified by the reduction factor.

\section{Reference}

1. Amstutz E. Buckling of pressure-shaft and tunnel linings $[\mathrm{J}]$. International Water Power and Dam Construction, 1970,(11): 391-399.

2. Jacobsen S. Buckling of circular rings and cylindrical tubes under external pressure[J]. International Water Power and Dam Construction, 1974,(12): 400-407.

3. Svoisky F M, Freishist A R. External pressure analysis for embedded steel penstocks[J]. International Water Power and Dam Construction, 1992,(1): 37-42.

4. SL281-2003 Design specification for steel penstocks of Hydroelectric stations[S] Beijing: China Water Conservancy and Hydropower Press, 2003. (in Chinese)

5. LI Ming, LIU Jie, WU Hegao, etc. Finite element buckling analysis on external pressure stability of stiffener ring penstock[J] Water Power, 2010, 36(4): 63-66.

6. MU Yuan, LU Xiaomin. Buckling analysis of ring stiffened steel penstocks with FEM[J]. Yellow River, 2014, 36(3): 92-95.

7. QI Wenbiao, ZHANG Ming, ZHENG Shuangling, etc. Comparative analysis of the elastic buckling solutions for ring-stiffened pipes under uniform external pressure[J] Journal of Hydraulic Engineering, 2018, 49(7): 877-885.

8. LIANG Yueying, WANG Jian, ZHENG Dongjian. Stability analysis of embedded pipe under external pressure [J]. Water resources and Power, 2006, 23(6): 33-35.

9. GB50766-2012 Code for manufacture installation and acceptance of steel penstocks in hydroelectric and hydraulic engineering [S] Beijing: China Planning Press, 2012. (in Chinese) 